\title{
Germanium Doping of Si Substrates for Improved Device Characteristics and Yield
}

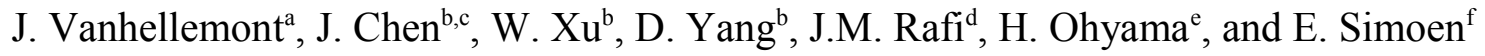 \\ ${ }^{a}$ Department of Solid State Sciences, Ghent University, B-9000 Ghent, Belgium \\ ${ }^{\mathrm{b}}$ State Key Lab of Silicon Materials, Zhejiang University, 310027 Hangzhou, P.R. China \\ ${ }^{\mathrm{c}}$ Institut für Angewandte Physik, TU Dresden, D-01062 Dresden, Germany \\ ${ }^{\mathrm{d}}$ CNM-CSIC, Campus U.A.B, 08193, Bellaterra, Barcelona, Spain \\ ${ }^{\mathrm{e}}$ Kumamoto National College of Technology, Kumamoto, 861-1102 Japan \\ ${ }^{\mathrm{f}}$ IMEC, B-3001 Leuven, Belgium
}

During the last decade the $300 \mathrm{~mm}$ Si wafer has been optimized and one is already studying $450 \mathrm{~mm}$ crystals and wafers. The increasing silicon crystal diameter shows two important trends with respect to substrate characteristics: the interstitial oxygen concentration is decreasing while the size of grown in voids (COP's) in vacancy-rich crystals is increasing.

The first effect is due the suppression of melt movements by the use of magnetic fields leading to a more limited transport of oxygen to the crystal. This and the decreasing thermal budget of advanced device processing leads to reduced internal gettering capacity. The increasing COP size is due to the combination of decreasing pulling rate and thermal gradient leading to a decreased void nucleation and increased thermal budget for void growth. The effect of Ge doping in the range between $10^{16} \mathrm{~cm}^{-3}$ and $10^{19} \mathrm{~cm}^{-3}$ on both COP's and oxygen precipitation will be discussed.

\section{INTRODUCTION}

During the last decade the $300 \mathrm{~mm} \mathrm{Si}$ wafer has been optimized and one is already actively exploring the next size increase which will be $450 \mathrm{~mm}$. With increasing crystal diameter the interstitial oxygen concentration is decreasing while the size of grown in voids (COP's) in vacancy-rich crystals is increasing. The first effect is due to the large melt in which melt movements are controlled and partly suppressed by the use of magnetic fields. This leads to a more uniform dopant incorporation but at the same time to a more limited transport of oxygen from the quartz crucible to melt and crystal. This reduced interstitial oxygen concentration and the lower thermal budget of modern device processing leads to reduced oxygen precipitation and thus internal gettering capacity of large diameter wafers. The second effect of increasing COP size (and decreasing density) is due to the combination of decreasing pulling rate and decreasing thermal gradient with increasing crystal diameter in order to avoid dislocation formation. This leads to a lower void nucleation rate and a larger thermal budget for void growth by vacancy diffusion. The standard approach to avoid void formation is by hot zone design leading to an intrinsic point defect lean crystal so that no intrinsic point defect clustering occurs during crystal cooling see e.g. (1) and references therein. A drawback of this approach is that the process window is rather narrow and involves the use of magnetic fields. Another, more recent approach to reduce both problems is by doping the Si crystal with a dopant that is not electrically active but enhances oxygen precipitation and reduces at the same time the va- 
cancy concentration available for void formation. Nitrogen fulfills to a large extent these requirements and nitrogen doped $\mathrm{Cz}$ wafers are commercially available and used already on a large scale. Recently, Londos et al (2-4) performed an extensive study of the influence of Ge doping on the behavior of oxygen and carbon impurity related complexes in electron irradiated $\mathrm{Si}$. The observations were explained by assuming that for concentrations below $10^{20} \mathrm{~cm}^{-3}$, Ge atoms act as temporary traps for vacancies and as such reduce the recombination rate of intrinsic point defects and Frenkel pairs. This has important consequences not only for radiation induced defect formation and population dynamics but most probably also for defect formation during crystal pulling. Vacancy trapping by Ge atoms was also claimed by Chen et al (5) based on density functional theory calculations although recent work of Chroneos et al (6) suggests that the impact of Ge is negligible compared to vacancy clustering as trap/sink for vacancies. Doping with Ge has also a beneficial effect on the strength of the silicon material and will thus reduce dislocation nucleation and propagation (7). It can be expected that Ge doping has a positive effect on the crystal yield in pulling processes and also on reducing processing induced dislocation generation. Although this strengthening effect is more pronounced for higher Ge concentrations than the one used in the present study, even for lower Ge concentration it was statistically shown that wafer breakage was reduced compared to standard Si wafers (8). In the present paper the effect of Ge doping in the range between $10^{16} \mathrm{~cm}^{-3}$ and $10^{19} \mathrm{~cm}^{-3}$ will be discussed and illustrated. Ge doping can be used to increase oxygen precipitation and to suppress thermal donor (9) and COP formation (10-12). Effects on diode characteristics and radiation induced defects are also illustrated $(9,13)$.

\section{CZOCHRALSKI GROWTH OF GE DOPED SI CRYSTALS}

In principle it is possible to grow $\mathrm{Ge}$ doped $\mathrm{Si}$ (or $\mathrm{Si}_{1-\mathrm{x}} \mathrm{Ge}_{\mathrm{x}}$ ) crystals using the standard Czochralski pulling process with $\mathrm{x}$ between 0 and 0.15 (14) although for $\mathrm{x}$ values above 0.01 , special attention is needed to avoid dislocation formation. For the present study, two 4-inch diameter, n-type CZ crystals were pulled by QL electronics, in collaboration with State Key Laboratory of Silicon Materials (Hangzhou, P. R. China). One of the crystals (GCZ) was doped with a Ge concentration of about $10^{19} \mathrm{~cm}^{-3}$, whereas the second crystal (CZ) was a standard one. Both crystals were grown under the same nominal pulling conditions and had therefore a similar resistivity and interstitial oxygen content $\mathrm{C}_{\mathrm{OI}}$ as listed in Table I. The interstitial oxygen content was measured with FTIR according to ASTM F 121-79, i.e. using the $4.815 \times 10^{17} \mathrm{~cm}^{-3}$ calibration constant. P-on$\mathrm{n}$ diodes, with an active area of $0.25 \mathrm{~cm}^{2}$, were processed on polished $<100>$ oriented wafers prepared from both crystals and were subjected to thermal treatments in $\mathrm{N}_{2} / \mathrm{H}_{2}$ or $\mathrm{N}_{2}$ annealing ambients at temperatures ranging between $250{ }^{\circ} \mathrm{C}$ and $450{ }^{\circ} \mathrm{C}$ and annealing times between $0.5 \mathrm{~h}$ and $5 \mathrm{~h}$. The impact of silicon substrate germanium doping on diode characteristics and on thermal donor formation was analyzed by means of capacitancevoltage $(\mathrm{C}-\mathrm{V})$, current-voltage (I-V) and recombination lifetime measurements based on microwave photo-conductance decay ( $\mu \mathrm{W}-\mathrm{PCD})(9)$.

TABLE I. Main specifications of the CZ Si and GCZ Si substrates used in the present study.

\begin{tabular}{lcc}
\hline Substrate & $\mathrm{CZ} \mathrm{Si}$ & $\mathrm{GCZ} \mathrm{Si}$ \\
Type & $\mathrm{n}$ & $\mathrm{n}$ \\
Orientation & $<100>$ & $<100>$ \\
Thickness $[\mu \mathrm{m}]$ & $525 \pm 15$ & $525 \pm 15$ \\
Resistivity $[\Omega \mathrm{cm}]$ & $23.7 \pm 2.4$ & $19.4 \pm 1.0$ \\
Average $\mathrm{C}_{\mathrm{OI}}\left[10^{18} \mathrm{~cm}^{-3}\right]$ & $1.54 \pm 0.08$ & $1.34 \pm 0.08$ \\
Ge concentration $\left[\mathrm{cm}^{-3}\right]$ & 0 & $\sim 10^{19}$ \\
\hline
\end{tabular}




\section{IMPACT OF GE DOPING ON CRYSTAL AND WAFER QUALITY}

The Flow Pattern Defect (FPD) and Secco Etch Pit Defect (SEPD) density in the CZ Si and GCZ Si materials were investigated by etching two wafers of each type vertically inserted in Secco etchant for different times. After this the FPD numbers were counted and the mean density was calculated. Typical optical micrographs obtained after 30 min Secco etching are shown in Fig. 1 revealing the presence of FPD's and SEPD's.

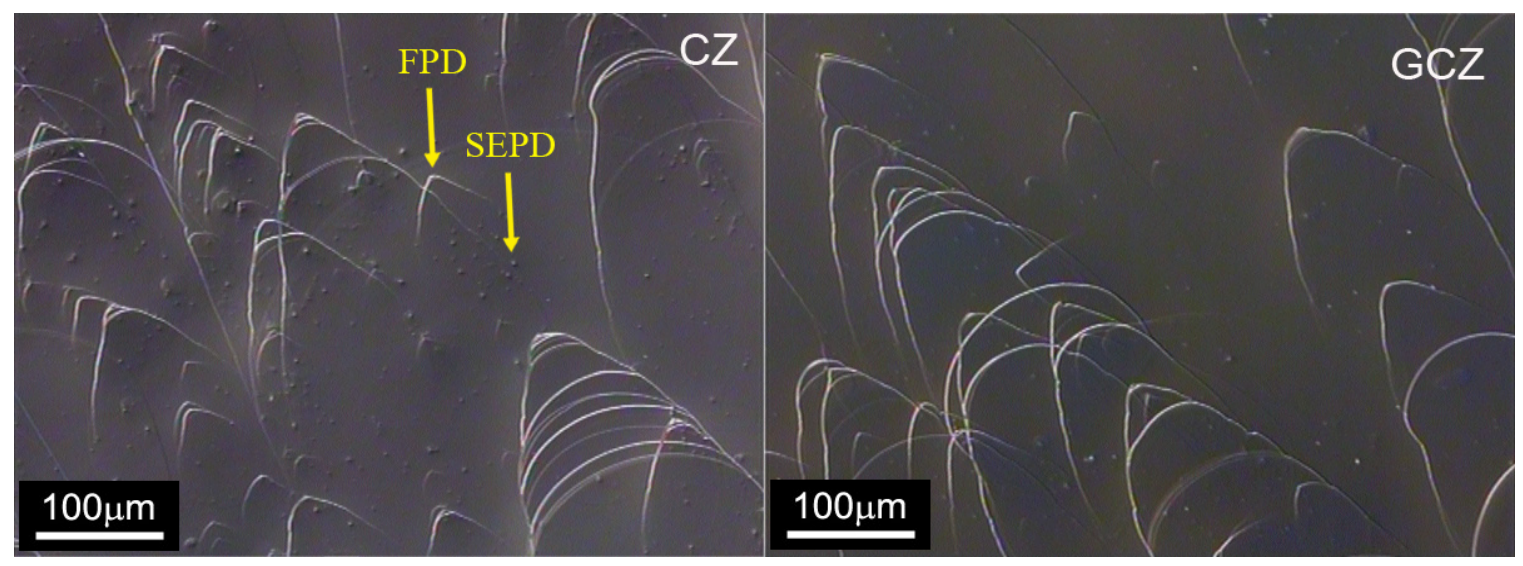

Figure 1. Optical micrographs showing FPD's and SEPD's after 30-min Secco-etching of 4 inch CZ (left) and GCZ (right) silicon wafers.

The observed FPD and SEP densities after 30 min Secco etching are shown in Fig. 2 together with results obtained on 5 inch wafers taken from different positions in crystals with different Ge concentrations (10). Also included are recent FPD data obtained by Arivanandhan et al (15) on 5 inch p-type (Ga doped) Si wafers as a function of Ge doping yielding FPD densities in excellent agreement with those obtained in the present work.
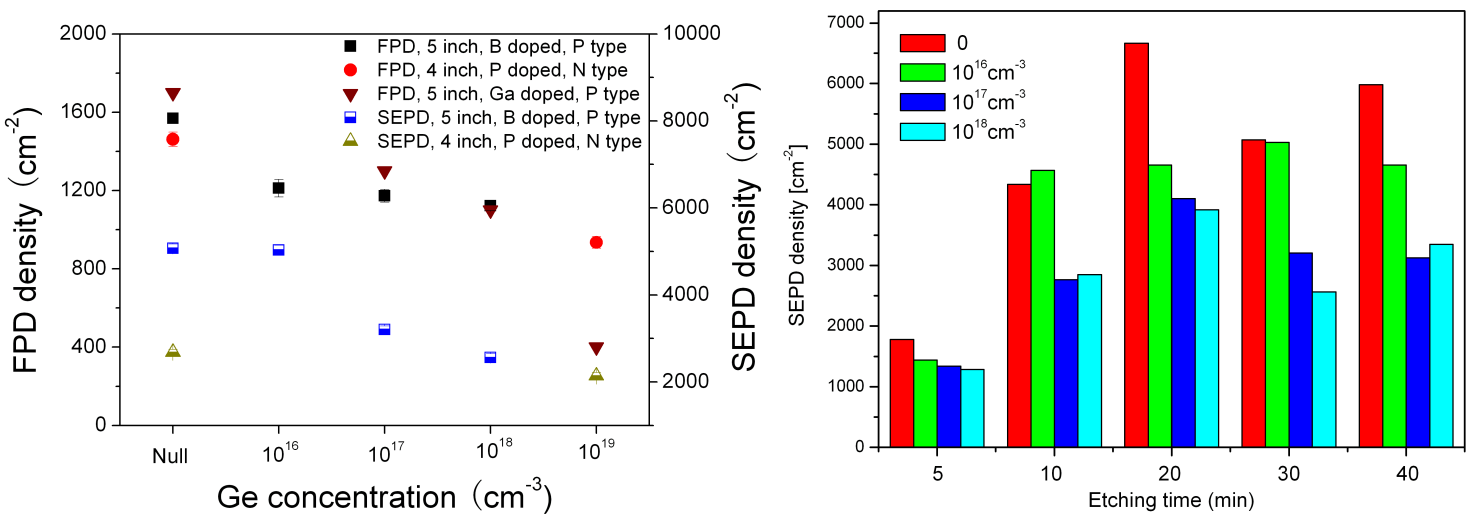

Figure 2. Left: FPD and SEPD densities observed in 4 inch wafers of the present study superimposed on results obtained on wafers prepared from the tail part of 5 inch asgrown CZ and GCZ Si crystals with different Ge concentrations (10). The wafers were etched at room temperature with Secco etchant for $30 \mathrm{~min}$. Recent data for Ga doped 5 inch as-grown CZ and GCZ Si wafers with different Ge concentrations are also included (15). Right: FPD and SEPD density as a function of Ge concentration and Secco etching time at room temperature observed in the wafers studied in (10). Values were averaged over 5 positions on the wafers. 
While for the CZ Si crystals, the FPD density in the tail and head part of the crystal is quite similar, for the GCZ Si crystals, the FPD densities in the tail part of the crystal are lower than in the head part. This can be understood by the fact that the Ge concentration increases towards the tail of the crystal due to the segregation coefficient (0.33) of Ge in Si. Also in the 4 inch wafers studied in the present work, the FPD (and SEPD) density is lower in the Ge doped crystal than in the standard Si crystal. In the present study, both for CZ Si and GCZ Si, the FPD density decreases with increasing crystal diameter while the SEPD density increases. This is the opposite behavior of the one reported before for Czochralski-grown silicon (16). The COP density was measured on 5 inch polished wafers which revealed an increase of COP density with increasing Ge content accompanied by a decrease of COP size (12). On the 4 inch wafers a similar trend is observed but the size of the COP's in the GCZ material becomes so small that most of them fall below the detection limit of the surface inspection tool.

\section{IMPACT OF GE DOPING ON DIODE CHARACTERISTICS AND THERMAL DONOR FORMATION}

Diodes were fabricated using a well established process with high device yield (17). Only small differences were observed between the diodes processed on both types of substrate (9). The reverse currents in the GCZ Si diodes were slightly higher than in their CZ Si counterparts although a somewhat higher free carrier concentration was also extracted for the GCZ Si diodes compared to the CZ Si ones. The higher reverse current levels in the GCZ Si diodes can be associated however with the lower generation lifetimes that were measured. Interestingly, an increase of the free carrier concentration is observed when subjecting the $\mathrm{CZ} \mathrm{Si} \mathrm{and} \mathrm{GCZ} \mathrm{Si} \mathrm{diodes} \mathrm{to} \mathrm{thermal} \mathrm{anneals} \mathrm{at} 450{ }^{\circ} \mathrm{C}$ (Fig. 3).
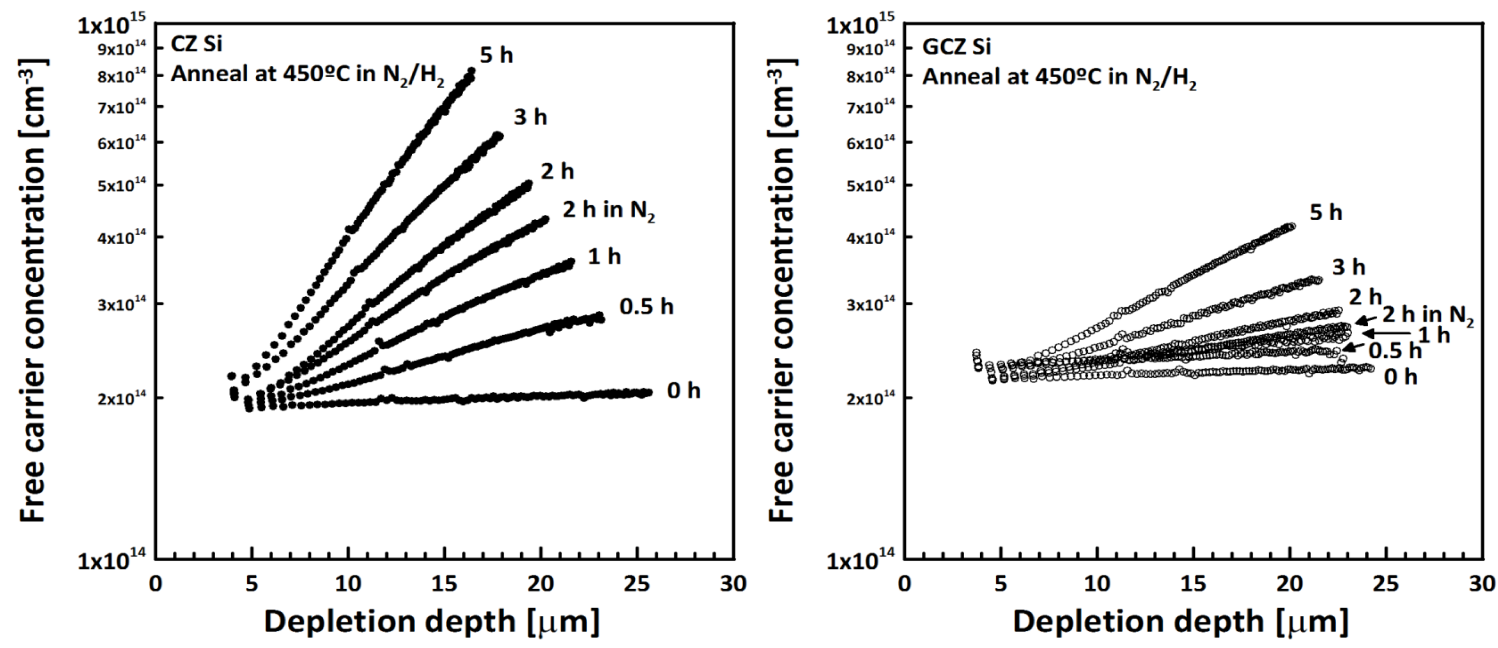

Figure 3. Free carrier concentration versus depletion width for CZ Si (left) and GCZ Si (right) diodes subjected to different thermal annealing conditions (9).

After a $5 \mathrm{~h}$ anneal and within the probed substrate depth that corresponds to a maximum applied reverse voltage of $100 \mathrm{~V}$, the carrier concentration increases by a factor of four and a factor of two for the CZ Si and GCZ Si substrates, respectively. The increase in the carrier concentration is due to the generation of oxygen-related thermal donors (TD) (18). and is illustrated in the left side of Fig. 4. The results show that the thermal donor (TD) generation rate for GCZ Si $\left(\approx 2.6 \times 10^{13} \mathrm{~cm}^{-3} \mathrm{~h}^{-1}\right)$ is nearly 5 times lower than the one ex- 
tracted for $\mathrm{CZ} \mathrm{Si}\left(\approx 1.26 \times 10^{14} \mathrm{~cm}^{-3} \mathrm{~h}^{-1}\right)$, in good agreement with previous results obtained on CZ Si substrates with similar oxygen contents (19). Furthermore, there is a faster TD formation in a $\mathrm{N}_{2} / \mathrm{H}_{2}$ ambient compared to $\mathrm{N}_{2}$ due to a hydrogen mediated increase of interstitial oxygen diffusivity (18).

\section{IMPACT OF GE DOPING ON RADIATION HARDNESS}

Diodes were $2 \mathrm{MeV}$ electron irradiated at room temperature with fluences ranging from $10^{14}$ to $10^{17} \mathrm{ecm}^{-2}$ using the electron accelerator at Takasaki Japan Atomic Energy Agency. Before and after irradiation, the current/voltage (I/V) and the capacitance/voltage $(\mathrm{C} / \mathrm{V})$ characteristics of the diodes were measured with applied voltages ranging from -20 to $1.5 \mathrm{~V}$ and 0 to $20 \mathrm{~V}$, respectively (13). The impact on the forward current is illustrated in the right part of Fig. 4. Due to an increasing resistivity of the substrate, the forward current decreases in both types of diodes, after $10^{17} \mathrm{ecm}^{-2}$ irradiation for a forward voltage larger than $\approx 0.7 \mathrm{~V}$. With respect to $\mathrm{I} / \mathrm{V}$ and $\mathrm{C} / \mathrm{V}$ characteristics, there is thus only a limited effect of $10^{19} \mathrm{~cm}^{-3} \mathrm{Ge}$ doping on electron irradiation hardness. Higher concentrations of Ge lead however to a clear radiation hardening of devices as observed in $\mathrm{Si}_{1-\mathrm{x}} \mathrm{Ge}_{\mathrm{x}}$ epitaxial devices for electron and neutron irradiation $(20,21)$ and for proton irradiation (22).
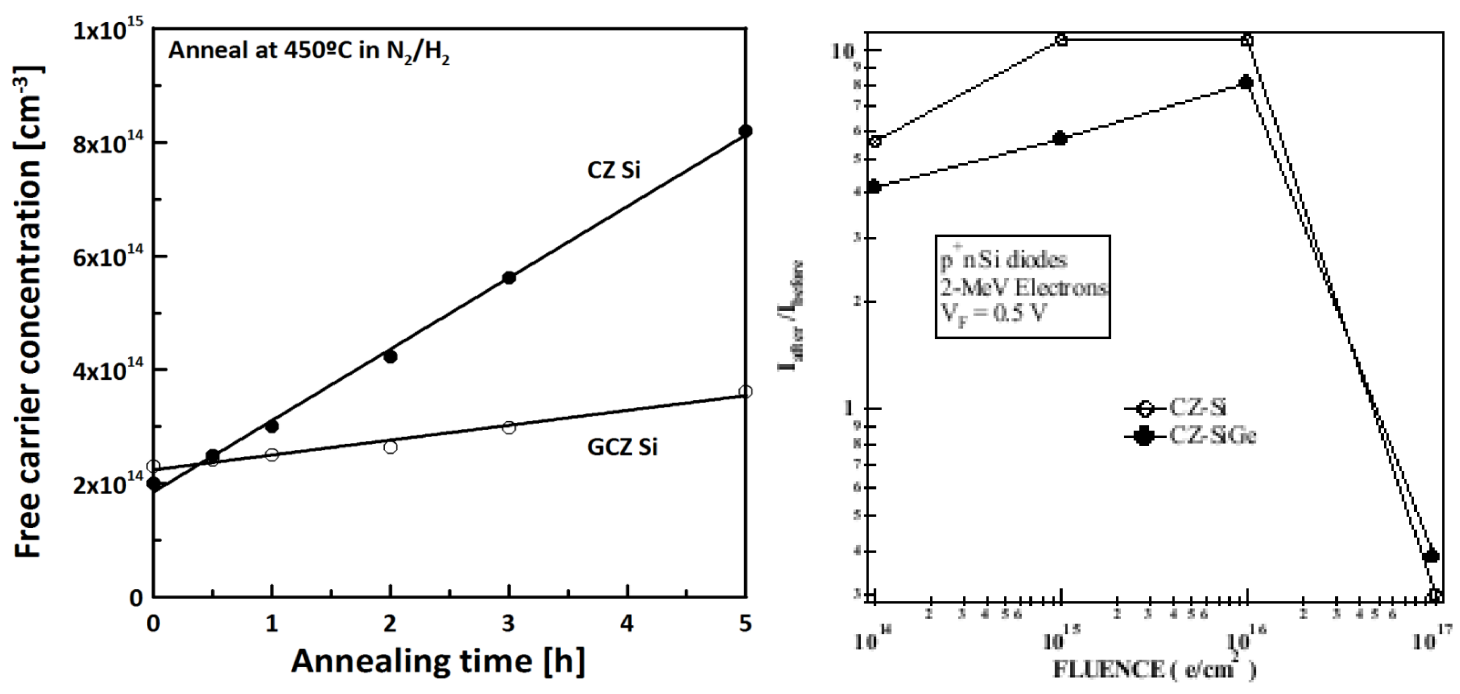

Figure 4. Left: Extracted free carrier concentration for CZ Si and GCZ p-on-n diodes subjected to different thermal annealing times at $450{ }^{\circ} \mathrm{C}$. The carrier concentrations correspond to the values for a depletion width of $16.5 \mu \mathrm{m}$ (9). Right: Normalized forward bias current of CZ Si and GCZ Si diodes after $2 \mathrm{MeV}$ electron irradiation (13).

\section{CONCLUSIONS}

Doping of silicon with germanium concentrations in the range between $10^{16}$ and $10^{19}$ $\mathrm{cm}^{-3}$ has a clear beneficial effect on crystal and wafer quality with respect to grown-in defect density and mechanical strength. The positive effects on diode characteristics (I/V and $\mathrm{C} / \mathrm{V}$ ) before and after electron irradiation are limited. On the other hand Ge doping clearly suppresses thermal donor formation which might be relevant for device processing. Further work is planned on GCZ Si substrates with higher Ge doping levels in the range between $10^{20}$ and $10^{21} \mathrm{~cm}^{-3}$. 


\section{ACKNOWLEDGMENTS}

J. Chen and J. Vanhellemont acknowledge the National Natural Science Foundation of China (NSFC, Grant No. 50832006 and 60906001) and the Research FoundationFlanders (FWO) for financial support. Part of this work was supported by the Inter-University Laboratory for the Joint Use of JAERI Facilities.

\section{REFERENCES}

1. J. Vanhellemont, P. Śpiewak, K. Sueoka and I. Romandic, Phys. Stat. Sol. C, 6, 1906 (2009).

2. C.A. Londos, A. Andrianakis, V. Emtsev and H. Ohyama, J. Appl. Phys., 105, 123508 (2009).

3. C.A. Londos, A. Andrianakis, V.V. Emtsev and H. Ohyama, Semicond. Sci. Technol., 24, 075002 (2009).

4. C.A. Londos, A. Andrianakis, V.V. Emtsev, G.A. Oganesyan and H. Ohyama, Physica B, 404, 4693 (2009).

5. J. Chen, T. Wu, X. Ma, L. Wang and D. Yang, J. Appl. Phys., 103, 123519 (2008).

6. A. Chroneos, R.W. Grimes and H. Bracht, J. Appl. Phys., 105, 016102 (2009).

7. I. Yonenaga, J. Cryst. Growth, 275, 91 (2005).

8. D. Yang, unpublished results.

9. J.M. Rafí, J. Vanhellemont, E. Simoen, J. Chen, M. Zabala, F. Campabadal, Physica B, 404, 4723 (2009).

10. D. Yang, X. Yu, X. Ma, J. Xu, L. Li and D. Que, J. Cryst. Growth, 243, 371 (2002).

11. D. Yang, J. Chen, H. Li, X. Ma, D. Tian, L. Li and D. Que, J. Cryst. Growth, 292, 266 (2006).

12. J. Chen, D. Yang, H. Li, X. Ma, D. Tian, L. Li and D. Que, J. Cryst. Growth, 306, 262 (2007).

13. H. Ohyama, J.M. Rafí, K. Takakura, E. Simoen, J. Chen and J. Vanhellemont, Physica B, 404, 4671 (2009).

14. N.V. Abrosimov, S.N. Rossolenko, W. Thieme, A. Gerhardt and W. Schröder, J. Cryst. Growth, 174, 182 (1997).

15. M. Arivanandhan, R. Gotoh, K. Fujiwara and S. Uda, J. Appl. Phys., 106, 013721 (2009).

16. T. Abe, Material Science and Engineering B, 73, 16 (2000).

17. C. Martínez, J.M. Rafí, M. Lozano, F. Campabadal, J. Santander, L. Fonseca, M. Ullán and A. Moreno, IEEE Trans. Nucl. Sci., 49, 1377 (2002).

18. E. Simoen, Y.L. Huang, Y. Ma, J. Lauwaert, P. Clauws, J.M. Rafí, A. Ulyashin, C. Claeys, J. Electrochem. Soc., 156, H434 (2009).

19. J.M. Rafí, E. Simoen, C. Claeys, Y.L. Huang, A.G. Ulyashin, R. Job, J. Versluys, P. Clauws, M. Lozano and F. Campabadal, J. Electrochem. Soc., 152, G16 (2005).

20. H. Ohyama, J. Vanhellemont, Y. Takami, K. Hayama, H. Sunaga, J. Poortmans, M. Caymax and P. Clauws, IEEE Trans. Nucl. Sci., 41, 2437 (1994).

21. H. Ohyama, J. Vanhellemont, Y. Takami, K. Hayama, H. Sunaga, J. Poortmans and M. Caymax, IEEE Trans. Nucl. Sci., 42, 1550 (1995).

22. H. Ohyama, K. Hayama, J. Vanhellemont, J. Poortmans, M. Caymax, Y. Takami, H. Sunaga, I. Nashiyama and Y. Uwatoko, Appl. Phys. Lett., 69, 2429 (1996). 